\title{
As relações entre ciência e política, especialização e democracia: a trajetória de um debate em aberto
}

\section{MAYA MITRE I}

\section{Introdução}

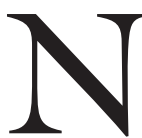

O INício dos anos 1970, o sociólogo Daniel Bell prognosticou o aguçamento da tensão provocada pela coexistência, no Ocidente, de duas tendências contraditórias: à igualdade e à burocratização. Para Bell (1973, p.8), o desejo dos indivíduos de participarem mais ativamente nos processos de tomada de decisões que afetam suas vidas, por um lado, e a crescente importância do componente técnico do conhecimento, por outro, formariam "o eixo do conflito social no futuro". Quase quarenta anos depois, a retórica da democracia desfruta de legitimidade inconteste entre políticos e acadêmicos ocidentais. Concomitantemente, vive-se um período de dependência notável, e provavelmente crescente, com relação ao conhecimento especializado - a chamada "era da expertise" (Fischer, 2010, p.1). Na mesma linha, a expressão "era da avaliação" (age of assessment) reflete a progressiva disseminação da prática de se basear políticas públicas em evidências científicas e dados técnicos (Rayner, 2003 , p.163-4). Em suma, o problema apontado por Bell soa mais atual do que nunca, com a diferença de que parece mais adequado, nos dias de hoje, substituir igualdade por democracia, e burocracia por expertise. ${ }^{1}$ Mais importante do que reconhecer a atualidade do paradoxo de Bell, entretanto, é perceber que ele não passa de uma entre outras formas de colocar o dilema ancestral de como equilibrar as relações entre a ciência - entendida de forma ampla, e intercambiável por termos como expertise ou conhecimento especializado - e a política.

De fato, o debate sobre as relações entre ciência e política finca suas raízes na filosofia clássica, assume feições modernas com Maquiavel, Hobbes e Bacon, ganha lugar de destaque na doutrina positivista de Comte, adota uma configuração alternativa com Weber e no pensamento liberal-democrático do século XX e, finalmente, vem a ser "desconstruído", a partir dos anos 1970, com o desenvolvimento de disciplinas como a sociologia do conhecimento científico e, mais recentemente, os estudos sociais da ciência e da tecnologia, os quais guardam uma estreita relação com as críticas teóricas aos modelos elitistas da democracia. 
Neste artigo, buscamos recuperar parte da trajetória do debate sobre as relações entre ciência e política, expertise e democracia, passando por distintas épocas, autores, tradições de pensamento e vertentes teóricas e disciplinares. No decorrer desse percurso, marcado pela passagem de uma visão metafísica da política, na Antiguidade, para outra inclinada à imanência, na Modernidade, examinamos de que modo a separação entre a ciência e a política cristalizou-se, nas democracias liberais modernas, no princípio da neutralidade da ciência e na crença de que essa deveria ser autogovernada - ou governada unicamente pelo sistema de avaliação por pares. Em seguida, consideramos os questionamentos do movimento construtivista a alguns dos pressupostos relativos à ciência moderna e a relação dessas críticas com teorias ditas "participativas" ou "deliberativas" da democracia. O objetivo é fornecer um arcabouço teórico que permita compreender melhor as origens e a substância dos atuais debates sobre a "democratização da expertise" e a participação pública em tomadas de decisão que envolvem temas tecnicamente complexos, mas moralmente sensíveis e de grande interesse social, tais como regulação de alimentos transgênicos, clonagem, diagnóstico pré-implantação e pesquisas com células-tronco embrionárias. Também buscamos mostrar os pontos de conexão entre discussões produzidas nos campos dos estudos sociais da ciência e da tecnologia e da teoria democrática. Por fim, discorremos brevemente a respeito das soluções para o problema da aparente incompatibilidade entre as demandas por maior democratização e participação pública e a crescente importância da técnica e do conhecimento especializado em nossa sociedade.

\section{Ciência e política na Antiguidade clássica: o Rei-Filósofo de Platão}

$\mathrm{O}$ vocábulo expert, tomado da língua inglesa, equivale, no português, a especialista ou perito. Já expertise - qualidade ou habilidade daquele que é expert - mostra-se de tradução menos simples para o nosso idioma. De toda forma, o uso de ambos tem se tornado comum na literatura que remete às relações entre a ciência - às vezes substituída pelo termo expertise - e à política, mesmo quando o tema é tratado com referência à Antiguidade clássica. Assim, no início do século XX, Lowell $(1913$, p.45) considerou que a pergunta sobre o papel dos experts em regimes democráticos, longe de nova, já havia sido confrontada dois mil anos antes. Pela cronologia apontada, não restam dúvidas de que o autor aludia a Platão. Mais recentemente, Nowotny (2003) iniciou uma discussão sobre a democratização da expertise referindo-se às críticas de Sócrates contra a irracionalidade da opinião pública.

À margem da pertinência ou não do uso dos termos expert e expertise para um período tão longínquo, o que nos interessa destacar, por ora, é que o Rei-Filósofo constitui a materialização, na Antiguidade clássica, da ideia de que "o mundo deve ser ordenado segundo os cânones da racionalidade superior a ser proporcionada pelos que sabem" (Schwartzman, 2008, p.19), ou de que a ciência (ou expertise) deve ser estendida para o domínio da política. Com efeito, 
para além de seu viés ascético, caracterizado pela desvalorização da experiência sensível, a filosofia platônica contém um projeto político. O processo de aprendizado do filósofo, que exige um afastamento gradual das realidades mundanas, não se dá em nome de uma vida meramente contemplativa; ao contrário, ele se exclui da sociedade para retornar a ela enquanto "governante autossuficiente, pronto para empregar seu conhecimento superior na sábia governança das massas ignorantes" (Brown, 2009, p.9). Isto é, enquanto se tornar um filósofo é uma escolha individual, o compartilhamento dos benefícios desse processo com a sociedade, através da condução da reforma social por meio da política, é uma obrigação moral e um caminho inevitável, mais do que honroso (Platão, 2006, p.303). Nessa linha, a filosofia política platônica é o exemplo mais conhecido da ideia de guardianship. Essa "perene alternativa à democracia" baseia-se no princípio de que "pessoas comuns" não são qualificadas para entender, e muito menos para defender, seus próprios interesses. Logo, somente um governo de "guardiães", moralmente competentes e com o conhecimento técnico e instrumental necessário, seria capaz de realizar o bem comum (Dahl, 1989).

Neste ponto, é preciso destacar os distintos fundamentos ontológicos em que se apoiam as reflexões sobre as relações entre ciência e política nos pensamentos antigo e moderno: metafísico e essencialista, o primeiro; imanente e relativista, o segundo. Na filosofia platônica há o postulado de que existe uma ordem imutável e perfeita a ser reconhecida pela razão, alicerçada em verdades absolutas que independem de nossas percepções, preferências e interesses. Sob essa perspectiva, por um lado, embora seja possível considerar, em um sentido amplo, o Rei-Filósofo como uma espécie de expert (isto é, um governante guiado não pelas opiniões, ou pela vontade da maioria, mas pelo conhecimento objetivo); por outro lado, cabe destacar que a sabedoria que ele possui não se refere - como hoje é comum supor - a uma parcela da realidade, mas à sua totalidade e à realização de fins últimos, que contemplariam a todos (cientes disso ou não). Com o advento da Modernidade, essa perspectiva irá cedendo espaço a outra, marcada pela imanência, na qual a racionalidade e o cálculo só podem ser aplicados a meios e fins relativos. A ruptura com a metafísica dos antigos traduz-se também na separação entre meios e fins, fatos e valores, a partir de uma visão secularizada e relativista, originando uma sociedade na qual Reis-Filósofos já não têm lugar, posto que o conhecimento da verdade se descola do conhecimento do bem.

\section{A moderna separação entre fatos e valores: de Maquiavel a Comte}

A separação entre fatos - a matéria-prima das ciências - e valores - a substância do conflito político - aparece com o despontar da Modernidade. Maquiavel, Descartes e Bacon, cada qual a seu modo, anteciparam essa ruptura ao unirem sua "política realista a uma nova ciência da natureza, a fim de transformar a antiga visão sobre o lugar da humanidade no mundo" (Weinberger, 1898, p.vii). À medida que essa tendência se firmava, ia ganhando corpo a ideia de que 
a ciência contribuiria não apenas para conquistar a natureza, mas também para controlar e ordenar a vida política, atormentada pelas voláteis e irreconciliáveis paixões humanas.

A noção de que a ciência, por ter acesso a verdades objetivas, pode contribuir para apaziguar os conflitos de interesses e de valores que fazem parte da política remonta à própria origem do pensamento político moderno. Ela já é perceptível em Maquiavel quando ele sugere, por exemplo, que "conselhos baseados em ideais normativos irão enfraquecer o príncipe", enquanto "conselhos realísticos [...] irão fortalecê-lo" (Brown, 2009, p.26). Na mesma trilha aberta por Maquiavel, a "nova ciência da política” de Hobbes funda-se justamente no princípio de que o conhecimento científico, com seu método "claro e exato", seria capaz de apontar o caminho da ação política racional, pondo fim às controvérsias e diferenças de opinião ocasionadas pelas imperfeições da natureza humana. Sob esta óptica, "a vitória final da ciência sobre a natureza dependeria da solução do problema da natureza humana”, o qual, segundo Hobbes, é "o problema da política" (Weinberger, 1976, p.865).

Na realidade, a aspiração hobbesiana de guiar a ação política de uma forma "científica" havia se manifestado pouco antes, e sob outra feição, na ideia, defendida pela primeira vez por Bacon, de que uma "elite técnica" deveria governar em nome da eficiência e da ordem (Fischer, 1990, p.67). Esse argumento é apresentado no Novo Atlantis, ficção que retrata uma sociedade governada por cientistas, a partir do consentimento de um líder "iluminado". O fato de que os cientistas de Bensalém, cidade onde a utopia baconiana se desenrola, detêm total autonomia, inclusive para ocultar segredos do Estado, parece explicar a longevidade dos cidadãos e a prosperidade da sociedade (Bacon, 1989, p.82). Como coloca Turner (2008, p.34), a ideia da extensão da ciência para o mundo social, "hoje familiar", era, na época de Bacon, totalmente "nova e radical". Mais do que isso, ela refletia a "hostilidade" desse filósofo à contestação e ao debate, práticas que viriam a integrar os pilares normativos do liberalismo.

Ressalvando o pioneirismo de Bacon na valorização de uma “intelligentsia técnica", coube a Henri de Saint-Simon o título de "pai da tecnocracia", visão que prega que a sociedade deve ser regida pela objetividade da ciência e da técnica. Para Saint-Simon, no futuro, a dominação do homem pelo homem seria substituída pela "administração das coisas" - uma visão que teve aderência entre marxistas-leninistas (Turner, 2008, p.35). Os escritos desse filósofo, que viveu as graves crises sociais que se sucederam às revoluções política e industrial na França, expressavam, precisamente, a esperança de que uma "linhagem nova de homens", isto é, engenheiros, administradores, planejadores - enfim, experts (Bell, 1973, p.342) - pudesse ascender ao poder a fim de "substituir as ideologias [políticas] divisivas prevalentes à época” e apaziguar o conflito de interesses (Fischer, 1990, p.69). É, inclusive, para inspirar esses novos líderes que Saint-Simon ordenou a composição de uma nova Marsellaise, o Chant des Industriels. 
É com Comte, entretanto, que a rejeição da normatividade em nome da objetividade e a ideia da extensão da ciência à sociedade atingem sua formulação mais sistemática. Para Comte, fatos e valores possuem status epistemológicos distintos: isto é, enquanto os primeiros advêm da experiência observável e são verificáveis, os segundos são inacessíveis à razão humana, não podendo ser provados como superiores ou inferiores, ou como verdades. Dado o caráter abstrato ou metafísico dos valores, portanto, a normatividade deveria ser ignorada. $\mathrm{O}$ "humanismo científico" de Comte, conhecido como positivismo, fundava-se na expectativa de que a razão científica seria capaz de chegar a uma fórmula única e suficiente para solucionar problemas das mais diversas naturezas. A utilização dos cânones epistemológicos das ciências físicas na compreensão das "leis da sociedade" é a base da "Lei [Comtiana] dos Três Estados", segundo a qual o "Estado Positivo" seria uma "síntese incomparável dos estados teológico e metafísico, que encontrariam na ciência o instrumento prodigioso da salvação eterna da humanidade" (Torres, 1957, p.12). Mais importante, o "Estado Positivo" seria aquele no qual os "ideais da liberdade e da igualdade seriam eventualmente suplantados pelos valores tecnocráticos da ordem e do progresso" (Fischer, 1990, p.71), firmando-se, assim, "um dos supostos mais difundidos no século XIX: o de que, graças à ciência, a humanidade poderia livrar-se da política" (Schwartzman, 2008, p.7). Segundo Turner (2008, p.36-7), o raciocínio de Comte era simples; isto é: "se a ciência é precisa, e se ela inclui o conhecimento do mundo social e da política, porque não afirmar que os cientistas devem governar os ignorantes, ou que devem governar através do controle da educação?” (livre tradução da autora).

\section{A perspectiva liberal e as relações entre ciência, política e democracia}

O pensamento de Comte, assim como o de Saint-Simon, e até mesmo o de Bacon, foi, em parte, uma reação aos princípios liberais em voga na época. Apesar disso, liberalismo e positivismo compartilhavam a crença de que a ciência seria capaz de solucionar os problemas sociais. Isto é, enquanto o positivismo acreditava na produção de "um plano para a organização da sociedade", o liberalismo sustentava que, deixados os indivíduos livres, sua razão "se agregaria naturalmente $[\ldots]$ para construir uma sociedade racional e eficiente" (Schwartzman, 2008, p.9). Posto de outra forma, ao invés de afirmar que o mundo "necessita de uma direção esclarecida, a ser exercida pelos homens de conhecimento superior", a perspectiva liberal parte do pressuposto de que "a sociedade humana tende naturalmente à racionalidade", desde que os homens e os cientistas sejam deixados livres (Schwartzman, 2008, p.19).

Apesar de se incluir na tradição liberal, Max Weber foi um duro crítico da ideia de que a ciência teria a "missão" de guiar a sociedade. Na Ciência como vocação, por exemplo, Weber retorna à República de Platão para contrastar as respostas "passada" e "presente" sobre o "valor da ciência". Segundo o autor, para "o homem helênico, cujo pensamento era totalmente político", o único 
propósito de engajar-se no processo do conhecimento era o de aprender a "agir como cidadão do Estado" (Weber, 1974a, p.167). Em outras palavras, o valor do conhecimento entre os antigos estava no fato de este permitir a apreensão do "bem" político. A ciência moderna, ao contrário, ao invés de prescrever valores, o que seria uma "ameaça à autonomia do indivíduo" (Kalberg, 2010, p.108), legitimar-se-ia pelo fato de ser um "método" neutro. Como coloca Weber, "Qual é o significado da ciência como vocação [...]?". Tolstoi deu a resposta mais simples com as palavras: "A ciência não tem sentido porque não responde à nossa pergunta, a única pergunta para nós: o que devemos fazer e como devemos viver?”. É inegável que a ciência não dá tal resposta (Weber, 1974a, p.169-70).

E emenda, com relação à distinção entre as vocações da ciência e da política, que

[...] uma coisa é apresentar os fatos, determinar as relações matemáticas ou lógicas, ou a estrutura interna dos valores culturais, e outra coisa é responder perguntas sobre o valor da cultura e seus conteúdos individuais, e a questão de como devemos agir na comunidade cultural e nas associações políticas. São problemas totalmente heterogêneos. Se perguntarmos por que não nos devemos ocupar de ambos os tipos de problemas na sala de aula, a resposta será: porque o profeta e o demagogo não pertencem à cátedra acadêmica. (ibidem, p.172-3)

A mensagem de Weber era, portanto, clara: as qualidades do cientista não coincidiam em absoluto com as do político. Mais ainda, a ciência jamais deveria ser instrumentalizada ou imbuída da obrigação de fornecer uma weltanschanung (Turner, 2008, p.42). Isso porque ela seria um simples método, desprovido de normatividade. Com efeito, a ciência moderna, na concepção de Weber, tem como objetivos avaliar a "adequação dos meios para [se] atingir determinado fim" (Kalberg, 2010, p.109) e produzir afirmações objetivas e verificáveis sobre a realidade. Tal neutralidade valorativa, por sua vez, só seria possível devido a uma espécie de "divisão de trabalho", a partir da qual outros campos, como o da política, tornar-se-iam por excelência os campos dos valores e da expressão da vontade humana subjetiva.

A despeito dessa tentativa de emancipação da ciência com relação à política (e vice-versa), tanto o liberalismo quanto o fascismo e o comunismo buscaram, nos anos 1930 e 1940, legitimar-se através da ciência e da tecnologia (Thorpe, 2008, p.67). Neste artigo, entretanto, iremos nos concentrar na relação que se estabeleceu entre a ciência e os regimes liberais democráticos.

Uma das formas mais comuns de se pensar a relação entre a ciência e a democracia passa pela crença de que a primeira é instrumental à segunda. Segundo Ezrahi (1990), democracias liberais como a norte-americana e a inglesa, historicamente, tomaram emprestada à ciência e à tecnologia a retórica da objetividade, neutralidade, impessoalidade e até mesmo da "apoliticidade". Isso se deu como forma de solucionar problemas intrínsecos à ordem política democrática, por exemplo: "como despolitizar ações oficiais ou administrativas rotineiras, 
como apresentar ações oficiais como sendo de interesse público, como tornar a ação pública accountable e como reconciliar a liberdade individual com a ordem social" (Thorpe, 2008, p.65). Em outras palavras, a ciência moderna funcionou como "material cultural" que legitimou as referidas democracias, principalmente através de uma "cultura visual" e de "testemunho", e ajudou a consolidar a ideia da política como lócus da objetividade e da representatividade, ao invés de âmbito da paixão irracional.

Para Edel (1944, p.703-4), produtos como a "máquina de votação, o rádio, as técnicas estatísticas, a teoria educacional, [e] a análise científica de preconceitos e de propaganda" são apenas alguns exemplos do que a ciência e a tecnologia podem fazer para "aumentar a participação dos homens na determinação da política social" e, dessa forma, contribuir para a democracia. $\mathrm{O}$ autor, entretanto, se junta ao coro dos que fazem a ressalva de que a ciência, entendida meramente como método, é capaz de servir tanto aos propósitos de um governo democrático quanto aos de uma ditadura. Nesse sentido, parece mais forte o seu argumento de que democracia e ciência são harmônicas porque se pautam por princípios semelhantes, a saber: a cooperação e o respeito à visão do próximo, a substituição da noção de necessidade pela de probabilidade e, consequentemente, uma abertura para novas ideias.

O paralelo entre a ciência e a democracia foi apontado também por Dryzek (1993, p.229), no contexto de um debate distinto. Segundo o autor, a recente valorização de uma "democracia discursiva", não implicaria necessariamente "o abandono da ciência, mas [antes] a radicalização seletiva de [certos] princípios científicos". Sob outra perspectiva, ao priorizar-se uma imagem específica da ciência, como descrição objetiva e avalorativa de "relações causais", oculta-se-lhe, em contrapartida, uma face bem mais amigável à democracia, isto é, aquela do "livre debate e [das] disputas nas quais a única força legítima é a do bom argumento".

Discutimos acima como a ciência pode ser considerada benéfica à democracia. A ideia recíproca, entretanto, também possui bastante ressonância, notadamente em países como os Estados Unidos. Como argumentou Tocqueville (1966), somente a democracia pode oferecer um solo fértil à ciência. Isso porque, dentre todas as formas de governo, só ela, paradoxalmente, seria capaz de blindar a ciência da interferência da política. Mais importante, só nas democracias financia-se a ciência sem interferir em seus objetivos.

A ideia de que a política deve se limitar a "fornecer dinheiro" aos cientistas, abstendo-se de lhes "fazer perguntas" (Brown, 2009, p.vii) - isto é, fiscalizá-los -, teve enorme peso nos Estados Unidos, justamente em uma época na qual a democracia norte-americana sentia-se ameaçada pelo comunismo. Nas décadas que se seguiram ao fim da Segunda Guerra Mundial, o argumento em prol de uma separação estrita entre ciência e política tornou-se um dos lemas da democracia liberal, refletindo uma reação tanto às teorias eugênicas do nazismo 
quanto ao comunismo. O famoso "social contract for science", nome pelo qual ficou conhecida a política de financiamento da ciência proposta em 1945, ainda durante o governo de Franklin Delano Roosevelt, traduzia bem esse espírito. Tal política consolidou-se sob a forma de um “contrato simples" entre o governo federal e os cientistas (Guston, 2000, p.37), através do qual o primeiro concordava em financiar tanto a pesquisa básica quanto a aplicada sem sujeitar os cientistas às "normas tradicionais de accountability" (Maynard-Moody, 1995, p.6). Em outras palavras, a proposta deixava clara, pela primeira vez, a necessidade de o governo assumir um papel mais ativo no financiamento da pesquisa básica, para o bem da nação. Além disso, reconhecia que o desenvolvimento tecnológico não prescinde de investimentos na chamada ciência pura (Bush, 1960).

A política científica norte-americana do pós-guerra calcava-se no pressuposto de que haveria uma "identidade de interesses entre o governo e a comunidade científica" (Price, 1965, p.4): isto é, de que o que é bom para a ciência é bom, consequentemente, para a nação. Tal pressuposto, por sua vez, baseava-se na crença de que a integridade e objetividade da atividade científica são protegidas por sua própria “estrutura cultural”, a qual é responsável por punir erros advindos tanto de fraquezas morais ou interesses quanto de falhas na representação dos fatos.

Polanyi parece seguir essa linha de argumentação ao advogar o princípio da autogovernança da ciência e a necessidade de protegê-la de tentativas de controle por parte de uma "autoridade única" ou de conferir-lhe "propósitos deliberados". A ideia por trás desse argumento é a de que a empreitada científica atinge os melhores resultados possíveis para a sociedade quando guiada pelo princípio “da coordenação espontânea de atividades individuais” (Polanyi, 1962, p.71). Posto de outra forma, a ciência não teria necessidade de "governança política sob a forma de planejamento porque já seria suficientemente 'governada' por suas tradições" (Turner, 2008, p.46). Isso não invalidaria, contudo, a possibilidade de que ciência e democracia convivessem de forma harmônica e respeitosa, principalmente através da concessão de autonomia à ciência pelo governo democrático. Apesar de sua ideia da "autocoordenação das atividades [científicas] independentes" associar-se explicitamente à metáfora da mão invisível, de Adam Smith, Polanyi (1962, p.72) vê importantes diferenças entre a ciência e o mercado; entre elas o fato de os cientistas, interagindo uns com os outros, não serem guiados pela esperança de ganho econômico, mas "motivados por códigos de conduta profissionais" ou por "satisfação intelectual".

Duas décadas antes de Polanyi, Merton já havia defendido a ideia de que os cientistas possuem uma ética profissional singular. Em seu paradigmático ensaio "A note on science and democracy", Merton define o etos da ciência moderna como sendo composto por quatro conjuntos de imperativos institucionais: universalismo, comunalismo, desinteresse e ceticismo organizado. Esses seriam vinculantes sobre a conduta do cientista por serem "corretos e bons" (Merton, 1942, p.118). A palavra "bom”, entretanto, deve ser entendida, nesse contexto, 
como funcional ao desenvolvimento científico. Isto é, acreditava-se que um conhecimento científico "confiável" só seria produzido na medida em que tais princípios "guiassem, efetivamente, as ações dos cientistas" (Mulkay, 1976, p.638).

A tentativa de Merton de definir as normas sociais da ciência faz parte de uma empreitada maior - da qual participaram também Popper e Kuhn dedicada a localizar as fronteiras entre a ciência e a não ciência ou as supostas características "singulares, necessárias e invariáveis que separam a ciência de outras práticas culturais e produtos, e que explicam seus sucessos" (Gieryn, 1983; 1995). Mas, enquanto as diferenças entre ciência e religião, por exemplo, dão margem a menos controvérsia, as fronteiras entre ciência e política são alvo de polêmicas até os dias de hoje.

\section{Delimitando as fronteiras entre a ciência e a política}

Ciência e política vivem um relacionamento paradoxal. Ao mesmo tempo que a ciência ganha autoridade a partir de sua suposta capacidade de orientar decisões sobre políticas públicas, uma aproximação excessiva com o campo político é uma das maiores ameaças à sua legitimidade (Gieryn, 1995, p.435-6). A recíproca também é verdadeira: ao mesmo tempo em que os políticos se valem da autoridade dos cientistas para defender seus pontos de vista, a aceitação do caráter meramente técnico das tomadas de decisão parece tornar quase dispensável a atuação dos primeiros, assim como o exercício do voto e outras formas de participação popular. ${ }^{2}$ É nesse sentido que se diz que "apenas boas cercas fazem da política e da ciência bons vizinhos" (Gieryn, 1995, p.436).

Tais “cercas", no entanto, são construídas predominantemente na esfera do discurso, isto é, na tentativa, por parte dos grupos de interesse, de monopolizar a definição de um problema como sendo "da política" ou "da ciência" e, consequentemente, determinar quem está apto a resolvê-lo. Esse processo é conhecido na literatura de estudos sociais da ciência e da tecnologia como boundary-work, ou demarcação de fronteiras. O processo de demarcação de fronteiras começou a despertar interesse no campo dos estudos sociais da ciência e da tecnologia a partir do artigo de Gieryn (1983) sobre os esforços dos cientistas para definir as particularidades de sua atividade intelectual, distinguindo-a de outras, consideradas por eles como pseudocientíficas ou não científicas. Tais particularidades, no entanto, longe de evidentes, seriam resultantes da ideologia profissional dos cientistas e de sua constante disputa para assegurar privilégios no "ecossistema intelectual" (Boulding apud Gieryn, 1983, p.783). Em outras palavras, o boundary-work seria uma atividade política, realizada com o objetivo de manter e/ou aumentar os recursos simbólicos e/ou materiais dos cientistas e defender sua autonomia profissional.

Seguindo a trilha aberta por Gieryn, Swedlow (2007) estuda o processo de demarcação de fronteiras entre membros reconhecidamente pertencentes à comunidade científica. Para ele, não se trata apenas de manter os outsiders para fora dos portões da ciência, mas de resolver disputas no interior da comunidade 
científica. É nesse sentido que muitos cientistas se valem da dicotomia "poluição" versus "pureza" para vencer disputas epistêmicas - isto é, asseguram que o argumento do colega, longe de puro, está poluído por interesses econômicos, políticos, ou simplesmente turvado pela incorreção dos dados.

O boundary-work, entretanto, assume uma conotação peculiar quando os cientistas são convocados a participar da formulação de políticas. Nesses casos, a autoridade cognitiva da ciência torna-se mais vulnerável, posto que o próprio processo político tende a expor as incertezas científicas (ou relativizar o peso das afirmações científicas) e os interesses dos atores envolvidos (Jasanoff, 1990, p.198). Assim, dá-se margem à afirmação de que a ciência é uma construção social, assim como suas diferenças com relação à política. É sobre essa ideia da construção social da ciência, ou construtivismo, que discorreremos a seguir.

\section{A construção social da ciência}

Uma das primeiras tentativas de apreender a ciência sob a óptica construtivista foi o chamado "The strong programme in the sociology of knowledge", de Bloor (1991). Antes dele, a sociologia do conhecimento, que sofrera forte influência de filósofos como Popper e Lakatos, trabalhava com base em uma espécie de divisão de tarefas, a partir da qual o sociólogo se contentava em buscar explicações apenas para a emergência e difusão de teorias falsas ou afirmações pseudocientíficas. Afinal, considerava-se que os fundamentos do conhecimento verdadeiramente científico jamais poderiam ser redutíveis a causas ou fatores sociais, localizando-se, portanto, fora do escopo da sociologia. Sob essa perspectiva, a sociologia do conhecimento era vista necessariamente como uma "sociologia do erro", da irracionalidade ou da "não ciência".

Disposto a combater essa estranha lógica, a partir da qual a sociologia do conhecimento deveria se ater a casos como o da frenologia ou às teorias de Lysenko, rejeitados pelo seleto clube da ciência, Bloor propôs tarefas mais assertivas a essa disciplina. Entre elas, a aderência aos princípios da causalidade (busca das condições, sociais ou não, que geram crenças ou estados do conhecimento), imparcialidade (explicar tanto asserções falsas como verdadeiras), simetria (considerar que os mesmos tipos de causa explicam crenças falsas e verdadeiras) e reflexividade (considerar que seus padrões de explicação são aplicáveis à própria sociologia). De forma sucinta, Bloor e seus seguidores passaram a argumentar que "fatos científicos" seriam "mais bem compreendidos como produtos de entendimentos socialmente negociados sobre o mundo natural" (Jasanoff, 1999 , p.62), ou que "interesse, ideologia e outros fatores aparentemente externos à ciência desempenham um papel tanto na aceitação quanto na rejeição de afirmações científicas" (Brown, 2009, p.164). Eis a plataforma a partir da qual se desenvolveria a chamada sociologia do conhecimento científico (sociology of scientific knowledge).

Collins foi outro precursor no desenvolvimento da sociologia do conhecimento científico. Para ele, a sociologia da ciência tinha sido criada com base 
no pressuposto de que "as respostas definitivas para questões [relativas à natureza] viriam da [própria] natureza, sendo o ser humano um mero mediador" no processo. Sob esta perspectiva, a sociologia se ocuparia somente das "respostas" fornecidas pelo "homem" e não das fornecidas pela "natureza", dado que aquelas não fariam parte do conhecimento científico. A sociologia do conhecimento científico, cuja "variação mais forte" ou radical é o relativismo, veio, por sua vez, contestar essa diferenciação, na medida em que buscava explicar de que modo o que é considerado conhecimento científico vem a ser tido como tal (Collins, 1983, p.266). Nessa linha, Collins, entre outros, mostrou como "métodos formais" ou "fatores científicos" são incapazes, por si sós, de "resolver diferenças de opinião sobre o que é uma adição adequada ao conhecimento científico" (Collins; Evans, 2002, p.239). Em outras palavras, a resolução de "controvérsias" científicas seria um processo socialmente negociado e "construído", mesmo que a portas fechadas. A partir dos chamados "estudos de laboratório" - isto é, observações antropológicas sobre as negociações que envolvem a construção do conhecimento no interior dos laboratórios -, os construtivistas se propuseram então a abrir "a caixa-preta" da produção de conhecimento científico e de tecnologia (Bijker; Pinch; Hughes, 1987), desvendando os "fatores sociais" envolvidos na produção do conhecimento supostamente objetivo e mostrando como fatos científicos "são gerados a partir de atos diários e contingentes da vida laboratorial” (Collins, 1983, p.266).

Assim como Collins, Latour também foi um dos pioneiros dos estudos de laboratório. Atualmente, no entanto, é mais frequentemente citado devido à sua intrigante "antropologia simétrica". Para ele, autores como Collins e Bloor teriam ido apenas até a metade do caminho em suas tentativas de desconstruir - ou mostrar como são socialmente construídas - as fronteiras entre a natureza e a sociedade. Isso porque, ao criticarem o realismo científico, teriam abraçado, em seu lugar, uma espécie de "realismo social", a partir do qual "fatores sociais adquirem o status de variáveis explanatórias fixas" (Brown, 2009, p.164). Em outras palavras, ao apontar a farsa por detrás de tentativas de utilizar o discurso da objetividade científica para evitar a deliberação política, a sociologia do conhecimento científico mantivera a barreira ontológica entre sujeitos (humanos) e objetos (não humanos), típica de uma visão pré-moderna do mundo (Latour, 2004). A única forma de evitar esse erro seria por meio da ampliação do princípio da simetria proposto por Bloor em uma direção totalmente inovadora: isto é, tratando, simetricamente, humanos e não humanos, como partes de um único todo. A separação entre natureza e sociedade, para Latour, teria sido feita sempre à custa da "coletividade", ou do "Terceiro Estado", composto tanto por humanos como por não humanos, interagindo a partir de redes híbridas e sociotécnicas. No interior dessas redes de interação entre humanos e não humanos, os cientistas não passam de mediadores. Entretanto, ao dar a conhecer seus trabalhos à sociedade, eles "purificam" tais alianças híbridas, apresentando-se como meros ventríloquos da natureza. Para Latour, tal estratégia de purificação, ou de antipolitização da 
ciência, seria fruto, entre outras coisas, do temor dos seres humanos com relação à incerteza (Brown, 2009, p.168-9) - temor esse que remete aos escritos de Nietzsche sobre a metafísica, a religião, a democracia e a ciência.

Neste ponto, cabe ressaltar que a crítica epistemológica elaborada pelo construtivismo, ao invés de "voltada para dentro", ou de interesse apenas no meio acadêmico, passa no teste da "relevância social" (Jasanoff, 1999, p.61). Como procuramos demonstrar acima, diferentemente da democracia, a ciência manteve-se por muito tempo blindada contra as pressões por maior accountability política, na medida em que se acreditava que os cientistas apenas "davam voz aos fatos" ou "espelhavam a realidade da natureza". Em outras palavras, a noção de "representação da natureza", diferentemente da de "representação política", teria o sentido de "estar no lugar de" (stand for) e não de "agir em nome de" (act for) (Brown, 2009, p.4-5). A “descoberta” construtivista de que o "núcleo epistêmico da produção de conhecimento científico" não é "segregado" da sociedade fez, entretanto, cair por terra a antiga crença de que a ciência é capaz de se autorregular - ou ser governada exclusivamente pelo sistema de avaliação por pares -, assim como de fornecer os fatos necessários para sustentar as melhores tomadas de decisão políticas (Felt; Fochler, 2008, p.489; Liberatore; Funtowicz, 2003, p.148). Nesse sentido, estendeu-se também para o campo da governança da ciência e da tecnologia a noção de que é importante engajar o público e ampliar a participação da sociedade civil.

Não é mera coincidência que a valorização do engajamento do "público leigo" em tomadas de decisão tecnocientíficas tenha ocorrido simultaneamente ao fortalecimento das demandas pela "democratização da democracia representativa" (as quais têm-se manifestado, no Brasil, em experiências como as dos orçamentos participativos, conselhos de políticas, entre outros) e - de maneira "construtivisticamente" consequente - à circulação acadêmica de modelos ditos participativos e/ou deliberativos da democracia. Afinal, se a ciência faz parte da sociedade e dialoga com esta, ela tende a ser afetada por suas transformações. Em The new production of knowledge, Gibbons et al. (2004) observam a lenta emergência de um novo paradigma de produção de conhecimento: o chamado "Modo 2", que viria a substituir o "Modo 1". Entre suas características, cabe destacar: (i) a geração de conhecimento em um "contexto de aplicação", que vai além da mera "aplicação" da "ciência pura", gerada em "ambientes teóricos/ experimentais"; (ii) a transdisciplinaridade, que não consiste necessariamente na junção de disciplinas preexistentes ou contribui para formar novas disciplinas; (iii) a diversificação dos loci de produção de conhecimento - especialmente devido ao avanço das tecnologias de informação -, assim como dos tipos de conhecimento produzidos; (iv) o caráter reflexivo do conhecimento, a partir do qual este se transforma em uma "conversação" entre sujeitos e objetos de pesquisa; e (v) o surgimento de novas formas de controle de qualidade (Nowotny; Scott; Gibbons, 2003, p.186-7). Tais mudanças, por sua vez, seriam parte de um processo mais amplo de "coevolução", a partir do qual a "Ciência Modo 
2" estaria se desenvolvendo em uma "Sociedade Modo 2" (Nowotny; Scott; Gibbons, 2001).

Uma ideia semelhante à de coevolução, e que vem ganhando cada vez mais adeptos entre os estudiosos da ciência e da tecnologia é a de que as "ordens natural e social" são produzidas em conjunto, ou relacionam-se através de um processo de "coprodução" (Jasanoff, 2006a). Tal noção é caracterizada por uma importante simetria entre a produção de ordem na natureza e na sociedade, evitando-se que, "mesmo que acidentalmente, ou sem intenção, se dê prioridade a qualquer uma das duas" (Jasanoff, 2006b, p.20).

Apesar do efeito libertador da "redefinição da ciência enquanto atividade social" (Collins; Evans, 2002, p.239), é fato que o movimento construtivista é hoje alvo de inúmeras críticas. As mais contundentes, e que têm engajado o maior número de estudiosos, referem-se, como era de esperar, à problematização da demanda pela ampliação da participação pública em tomadas de decisão relativas à ciência e à tecnologia. Adiante, discorreremos brevemente sobre algumas delas e mostraremos as alternativas propostas.

\section{A democratização da expertise e suas principais críticas}

Nos dias de hoje, é difícil encontrar entre os cientistas sociais alguém que se levante para defender abertamente a substituição da democracia por outra forma de governo. Ainda assim, o questionamento da capacidade dos cidadãos de "deliberar inteligentemente a respeito de temas complexos de política pública", apesar de "desconfortável", continua sendo "fundamental" (Fischer, 2010, p.49). Recentemente, no Brasil, o debate sobre a união civil entre pessoas do mesmo sexo trouxe à tona o argumento de que questões dessa natureza não devem ser deliberadas nos parlamentos, e sim por "elites" - no caso, os membros do Supremo Tribunal Federal ${ }^{3}$ - menos sujeitas às pressões da opinião pública. Se a abertura à participação pública a respeito de questões moralmente sensíveis e controversas nem sempre é considerada a alternativa mais prudente, o que dizer então de temas que, além de mobilizarem valores, envolvem conhecimento especializado em ciência e tecnologia? Até que ponto, nesses casos, o consenso sobre os limites da objetividade da ciência e o caráter "humano, demasiado humano" dos cientistas deve retirar-lhes qualquer prerrogativa de tomada de decisão? Posto de outra forma, como equacionar conhecimento especializado e participação a fim de garantir tanto a legitimidade quanto a qualidade da governança tecnocientífica?

A despeito de a atual "onda democratizante" ter atingido os estudos sociais da ciência e da tecnologia, grande parte dos acadêmicos nesse campo disciplinar questiona a valorização apriorística da participação do público leigo em tomadas de decisão tecnocientíficas, e não descarta a importância do conhecimento especializado nas sociedades contemporâneas. Até mesmo os mais comprometidos com a crítica ao modelo "elitista" da expertise, segundo o qual os experts teriam acesso não mediado a verdades categóricas, admitem que a alternativa "relati- 
vista" - isto é, a ideia de que a ciência pode ser instrumentalizada para apoiar qualquer argumento político - é falha.

Críticas pontuais têm sido dirigidas a deficiências de experiências participativas específicas, tais como grupos focais, conferências de consenso (consensus conferences), avaliações participativas de tecnologias (participatory technological assessments), audiências e consultas públicas, júri de cidadãos (citizen juries) e conselhos comunitários consultivos (community advisory boards). Observações mais amplas, entretanto, apontam para a distância entre as expectativas normativas e os resultados das experiências práticas. Como coloca Rayner (2003, p. 165 ), por exemplo, muitos cientistas sociais e $\mathrm{ONG}$, ao defenderem a participação pública nas tomadas de decisão tecnocientíficas, se apoiam nos modelos deliberativos da democracia. Ao fazerem isso, constroem uma idealização do cidadão participante que "mascara as realidades da indiferença, da política e do poder". Outra crítica nessa linha refere-se à falta de "representatividade, ao desequilíbrio de poder e à ausência de mandato político" daqueles envolvidos em procedimentos participativos (Bora; Hausendorf, 2006, p.479), assim como à ausência de embasamento dessas formas de participação "nas instituições da democracia representativa" (Abels; Bora apud Bora; Hausendorf, 2006, p.479). Levando em conta esses fatores, parte da literatura tem se esforçado para identificar modelos conceituais que "desafiem a noção do monopólio do conhecimento por um grupo seleto" e protegido de demandas de accountability (Liberatore; Funtowicz, 2003), sem se desfazer completamente do valor do conhecimento ou correr o risco de abrir as portas para a irracionalidade. A ideia da inauguração de uma "Terceira Onda" nos estudos sociais da ciência e da tecnologia, caracterizada pela tentativa de construir uma "teoria normativa da expertise", partindo do princípio de que existe, de fato, um conjunto específico de critérios de validação para a ciência e a tecnologia, faz parte dessa tendência.

Segundo Collins e Evans (2003, p.436), a estratégia de colocar um limite à extensão da participação nas questões de ciência e tecnologia parte do princípio de que, ainda que se reconheça que "a expertise é essencialmente imprecisa [...], e mais amplamente distribuída na sociedade do que antes se pensava", ela ainda possui grande valor nas tomadas de decisão. Uma das primeiras iniciativas propostas pelos autores para a concretização da empreitada de "martelar um prego na parede de gelo do relativismo" - leia-se, construtivismo - com "delicadeza suficiente para não destruir o edifício como um todo" (Collins; Evans, 2002, p.240) seria a de substituir o conceito de "expertise leiga" pelo de "expertise baseada na experiência”. Assim, evitar-se-ia a utilização de uma expressão "incongruente", ao mesmo tempo que se reconheceria que o conjunto de pessoas capazes de "contribuir para a ciência de um campo" não se restringe àqueles cuja expertise é reconhecida por "certificação", isto é, por um diploma ou grau acadêmico (Collins; Evans, 2002, p.238). 
Seguindo linha semelhante, Evans e Plows (2007) afirmam que, sob o guarda-chuva da expertise devem ser incluídos, além dos cientistas, "ativistas ou outros com experiência especializada relevante", em oposição aos "cidadãos leigos" ou, simplesmente, os "não experts". Para eles, entretanto, é preciso deixar claro que experts "não certificados" não podem, devido simplesmente à informalidade de sua expertise, alegar que estão falando "em nome dos cidadãos em geral". Da mesma forma como as noções de "fato" e "objetividade" são colocadas em xeque, experts de todo tipo devem ser considerados como "representantes de comunidades epistêmicas particulares, tais como cientistas, trabalhadores do campo, ativistas ambientais, agrobusiness etc." (Evans; Plows, 2007, p.829). Logo, a mera ampliação da concepção de expertise não representa por si só uma solução para o problema da democratização da ciência ou para o suprimento da lacuna entre expertise e democracia, uma vez que os leigos continuam sendo excluídos dos processos de tomada de decisão. É nesse sentido que, muito mais do que distribuir generosamente o título de expert, ou dizer que experts não certificados são capazes, da mesma forma que doutores, de "contribuir para a ciência do campo em análise" (Collins; Evans, 2002, p.254), a democratização da expertise deve envolver uma abertura para novos enquadramentos. Não se trata, portanto, de permitir que "pessoas com expertise autêntica, mas não reconhecida [formalmente]", tenham acesso a "deliberações especializadas" sobre questões, como por exemplo, os OGM. Trata-se, ao invés disso, de acolher novas questões, ignoradas nos discursos tradicionais, ou formas alternativas de olhar para os mesmos problemas (Wynne, 2003). Nas palavras de Jasanoff (2003, p.397-8):

O engajamento do público é necessário a fim de testar e contestar o enquadramento das questões que os experts são chamados a resolver. Sem essa supervisão crítica, os experts, frequentemente, têm oferecido conselhos irrelevantes sobre questões erradas ou mal formuladas. Além disso, como vimos, a expertise é constituída dentro das instituições, e instituições poderosas podem perpetuar formas injustas e infundadas de olharmos para o mundo, a menos que sejam colocadas sob o escrutínio das pessoas leigas, capazes de avisar quando o imperador está sem roupas. (livre tradução da autora)

Essa ideia aparece também entre teóricos da democracia deliberativa e entre feministas. Para estes, a "ênfase liberal na autoridade de determinados tipos de razão", e principalmente a "razão científica", negligencia "pontos de vista de grupos à margem da cultura dominante" e "restringe a agenda da discussão pública" (Fischer 2010, p.79). No caso dos estudos sociais da ciência e da tecnologia, a crítica ao princípio "universalista moderno" de que a deliberação produzirá o consenso sobre o bem comum se traduz na exaltação à diferença, à pluralidade de razões, à cultura e até mesmo ao dissenso (Lövbrand; Pielke; Beck, 2010). É a partir daí que surgem noções como a de "epistemologia cívica" (Jasanoff, 2007), que levam o peso da cultura nas diferentes formas de lidar com evidências científicas e conhecimento. 


\section{Considerações finais}

Neste artigo procuramos mostrar como as relações entre a ciência e a política, a expertise e a democracia aparecem no pensamento ocidental desde os seus registros mais antigos. Argumentamos que a balança entre expertise e democracia vem, gradualmente, se inclinando na direção da ampliação da participação da sociedade civil e da contestação do modelo tecnocrático de tomada de decisão, em sintonia com a tendência mais ampla de se "democratizar" a democracia representativa. Por fim, vimos que o élan democratizante não tem poupado o campo das tecnociências, valorizando a opinião do público leigo na formulação das normas que devem regular as pesquisas, assim como na utilização de seus resultados. A análise dessa trajetória, entretanto, mostra que a obtenção de equilíbrio na relação entre ciência e política, e/ou expertise e democracia, envolve um desafio complexo, uma vez que a desconfiança nos experts tanto pode comprometer a racionalidade das decisões tomadas, quanto favorecer o autoritarismo ou ir de encontro ao interesse público. Ao mesmo tempo, apostar na tecnocracia ou na expertocracia traz prejuízos à qualidade do processo democrático.

A obliteração das fronteiras entre experts e não experts, ou o "alargamento" do conceito de expertise para que possa incluir, por exemplo, a "expertise não certificada", representa por vezes uma solução ingênua. Isso porque o "expert não certificado", uma vez admitido a um núcleo decisório, nada mais é do que um representante político de setores específicos cuja presença naquele fórum tenha sido institucionalmente determinada. O problema do autoritarismo também deve ser levantado. Isso porque, dependendo do contexto sobre o qual estamos falando, o limite à participação dos experts pode vir ao preço de uma maior centralização do poder nas mãos do Estado, em geral distribuída entre políticos eleitos e burocratas.

A confiança excessiva nos experts, por outro lado, parece reforçar uma concepção meramente formal da democracia. Isto é, quanto mais "técnica" é considerada uma questão, menos espaço abre para o levantamento de questões políticas substantivas, tais como as perguntas sobre "o tipo de sociedade em que queremos viver" e o lugar da ciência nesta sociedade, ou sobre como devem ser estabelecidas, no caso da ciência e da tecnologia, as fronteiras entre a cura e o melhoramento, a eugenia "positiva" e a "negativa", a utopia e a distopia. ${ }^{4}$

Em suma, acreditamos que os dilemas "participacionistas" enfrentados pelos estudiosos da ciência e da tecnologia sejam semelhantes aos enfrentados pelos teóricos da democracia. A sutileza, entretanto, está em atentar para certas especificidades dos temas científicos, para o peso político-eleitoral de assuntos dessa natureza em cada contexto e, principalmente, para a trajetória das relações históricas entre cientistas e Estado, ciência e política em cada sociedade, a fim de encontrar soluções sob medida.

A autora agradece ao professor Bruno Pinheiro Wanderley Reis por seus comentários, e à Capes e à Fapemig por seu apoio financeiro durante o doutorado e pós-doutorado, respectivamente 
Notas

1 Não pretendo sugerir que os termos expertise e burocracia sejam intercambiáveis, mesmo porque o burocrata é um tipo bastante específico de expert, que integra o quadro de funcionários do Estado. Também é importante ressaltar que Bell não se vale do termo "expert", mas atribui o mesmo lugar, na "era pós-industrial", a burocratas, profissionais, cientistas e engenheiros - em suma a uma "intelligentsia técnica" cujo conhecimento especializado vai de encontro à noção da participação popular na política.

2 Isso talvez explique a combinação, em países industrializados, entre a confiança nos experts e o declínio da participação eleitoral (ver, por exemplo, Rayner, 2003).

3 Nesse caso específico, tratava-se porém de uma questão de interpretação da Constituição e não de revogação de uma deliberação legislativa anterior, o que certamente seria muito mais problemático sob o ponto de vista da democracia.

4 Sobre estes debates ver, por exemplo, Habermas (2004) e Sandel (2007).

\section{Referências}

BACON, F. The New Atlantis. In: WEINBERGER, J. (Comp.) New Atlantis and the Great Instauration. Wheeling: Harlan Davidson, 1989. p.37-83.

BELL, D. The coming of post-industrial society. A venture in social forecasting. New York: Basic Books, 1973.

BIJKER, W.; PINCH, T.; HUGHES, T. The social construction of technological system. Cambridge: The MIT Press, 1987. p.17-50.

BLOOR, D. The strong programme in the sociology of knoweldge. In: Knowledge and social imagery. Chicago: University of Chicago Press, 1991. p.3-23.

BORA, A.; HAUSENDORF, H. Participatory science governance revisited: normative expectations versus empirical evidence. Science and Public Policy, Guildford, v.33, n.7, p.478-88, Aug. 2006.

BROWN, M. B. Science in democracy. Expertise, institutions and representation. Cambridge: The MIT Press, 2009.

BUSH, V. Science, the endless frontier. A report to the President on a Program for Postwar Scientific Research. Washington, D.C.: National Science Foundation, 1960.

COLLINS, H. M. The sociology of scientific knowledge: Studies of Contemporary Science. Annual Review of Sociology, Palo Alto, v.9, p.265-85, Aug. 1983.

COLLINS, H. M.; EVANS, R. The third wave of science studies: studies of expertise and experience. Social Studies of Science, Los Angeles, London, New Dheli, Singapore, v.32, n.2, p.235-96, Apr. 2002.

COLLINS, H. M.; EVANS, R. King Canute meets the Beach Boys: response to the Third Wave. Social Studies of Science, Los Angeles, London, New Dheli, Singapore, v.33, n.3, p.435-52, Jun. 2003.

DAHL, R. Democracy and its critics. New Haven: Yale University Press, 1989.

DRYZEK, J. S. Policy Analysis and Planning: from science to argument. In: FISCHER, F.; FORRRESTER, J. (Ed.) The argumentative turn in Policy Analysis and Planning. Durham; London: Duke University Press, 1993. p.213-32. 
EDEL, A. The relations of science and democracy. The Journal of Philosophy, v.41, n.26, p.701-10, 1944.

EVANS, R.; PLOWS, A. Listening without prejudice? Re-discovering the value of the disinterested citizen. Social Studies of Science, Los Angeles, London, New Dheli, Singapore, v.37, n.6, p.827-53, Dec. 2007.

EZRAHI, Y. The descent of Icarus. Cambridge, MA: Harvard University Press, 1990.

FELT, U.; FOCHLER, M. The Bottom-Up Meanings of the concept of Public Participation in Science and Technology. Science and Public Policy, Guildford, v.35, n.7, p.489-99, Aug. 2008.

FISCHER, F. Technocracy and the politics of expertise. Newbury Park: Sage, 1990.

Democracy and expertise. Reorienting policy inquiry. Oxford; New York: Oxford University Press, 2010.

GIBBONS, M. et al. New production of knowledge: Dynamics of science and research in contemporary societies. London: Sage, 2004.

GIERYN, T. Boundary-work and the Demarcation of Science from Non-sciences: Strains and Interests in Professional Ideologies of Scientists. American Sociological Review, Washington, v.48, n.6, p.781-95, Dec. 1983.

. The boundaries of science. In: JASANOFF, S. et al. (Ed.) Handbook of Science and Technology Studies. Thousand Oaks: Sage Publications, 1995. p.393-443.

GUSTON, D. H. Understanding the social contract for science. In: __. Between politics and science. New York: Cambridge University Press, 2000. p.37-63.

HABERMAS, J. O futuro da natureza humana. Trad. Karina Jannini. São Paulo: Martins Fontes, 2004.

JASANOFF, S. The fifth branch. Science Advisers as Policy-Makers. Cambridge: Harvard University Press, 1990.

STS and Public Policy: Getting beyond Deconstruction. Science, Technology and Society, v.4, n.1, p.59-72, March 1999.

Breaking the waves in Science Studies: Comment on H. M. Collins and Robert Evans, "The Third Wave of Science Studies". Social Studies of Science, Los Angeles, London, New Dheli, Singapore, v.33, n.3, p.389-400, June 2003.

. The Idiom of Co-Production. In: States of Knoweldge. The co-production of science and social order. New York: Routledge, 2006a. p.1-12.

. Ordering knowledge, Ordering society. In: States of knoweldge. The co-production of science and social order. New York: Routledge, 2006b. p.13-45.

Designs on Nature. Science and democracy in Europe and the United States. Princeton: Princeton University Press, 2007.

KALBERG, S. Max Weber. Uma introdução. Trad. Vera Pereira. Rio de Janeiro: Jorge Zahar, 2010.

LATOUR, B. How to bring the collective together. In: _. Politics of Nature: How to bring the sciences into democracy. Cambridge, MA: Harvard University Press, 2004. p.53-90. 
LIBERATORE, A.; FUNTOWICZ, S. “Democratising” Expertise, "Expertising” Democracy: what does this mean, and why bother? Science and Public Policy, Guildford, v.30, n.3, p.146-150, Jun 2003.

LÖVBRAND, E.; PIELKE JR., R.; BECK, S. et al. A democracy paradox in studies of science and technology. Science Technology and Human Values, v.36, n.4, p.474-96, Aug. 2010.

LOWELL, A. L. Expert administrators in popular government. The American Political Science Review, Los Angeles, v.7, n.1, p.45-62, Feb. 1913.

MAYNARD-MOODY, S. Managing controversies over science: The case of Fetal Research. Journal of Public Administration Research and Theory: J-PART, Oxford, v.5, n.1, p.5-18, Jan. 1995.

MERTON, R. K. A note on science and democracy. Journal of Legal and Political Sociology, East Hampton, v.1, p.115-126, 1942.

MULKAY, M. J. Norms and ideology in science. Social Science Information, v.15, n.4/5, p.637-656, 1976.

NOWOTNY, H. Dilemma of expertise. Democratising expertise and socially robust knowledge. Science and Public Policy, v.30, n.3, p.151-6, 2003.

NOWOTNY, H.; SCOTT, P.; GIBBONS, M. Re-thinking science. Knowledge and the Public in an Age of Uncertainty. Cambridge: Polity, 2001.

. "Mode 2" Revisited: The New Production of Knowledge. Minerva, New York, v.41, p.179-94, 2003.

PLATÃO. A República. Trad. Anna Lia Amaral de Almeida Prado. São Paulo: Martins Fontes, 2006.

POLANYI, M. The Republic of Science. Minerva, New York, v.1, p.54-72, 1962.

PRICE, Don K. Escape to the endless frontier. In: _. The scientific estate. Cambridge: Harvard University Press, 1965. p.1-20.

RAYNER, S. Democracy in the age of assessment: reflections on the roles of expertise and democracy in public-sector decision making. Science and Public Policy, Guildford, v.30, n.3, p.163-70, June 2003.

SANDELL, M. The case against perfection. Ethics in the Age of Genetic Engineering. Cambridge; London: The Belknap Press of Harvard University, 2007.

SCHWARTZMAN, S. Ciência, universidade e ideologia: a política do conhecimento. Rio de Janeiro: Centro Edelstein de Pesquisas Sociais, 2008.

SWEDLOW, B. Using the Boundaries of Science to do Boundary-Work among Scientists: Pollution and Purity Claims. Science and Public Policy, Guildford, v.34, n.9, p.63343, Nov. 2007.

THORPE, C. Political Theory in Science and Technology Studies. In: HACKETT, E. J.; AMSTERDAMSKA, O.; LYNCH, M.; WAJCMAN, J. The Handbook of Science and Technology Studies. 3.ed. Cambridge; London: The MIT Press, 2008. p.63-82.

TOCQUEVIlle, A. de. Democracy in America. Ed. J. P. Mayer and M. Lerner. Trad. George Lawrence. New York, Evanston: Harper and Row, 1966.

TORRES, J. C. de O. O positivismo no Brasil. Rio de Janeiro: s. n. 1957. 
TURNER, S. The Social Study of Science before Kuhn. In: HACKETT, E. J. et al. The Handbook of Science and Technology Studies. 3.ed. Cambridge; London: The MIT Press, 2008. p.33-62.

WEBER, M. A ciência como vocação. In: Ensaios de Sociologia. 3.ed. Org. H. Gerth, W. Milss. Trad. Waltensir Dutra. Revisão Fernando Henrique Cardoso. Rio de Janeiro: Zahar Editores, 1974a. p.154-83.

A política como vocação. In: Ensaios de Sociologia. Org. H. Gerth, W. Milss. Trad. Waltensir Dutra. Revisão Fernando Henrique Cardoso 3.ed. Rio de Janeiro: Zahar Editores. 1974b. p.97-153.

WEINBERGER, J. Science and Rule in Bacon's Utopia: an Introduction to the Reading of the New Atlantis. The American Political Science Review, Los Angeles, v.70, n.3, p.865885, sept. 1976.

. Introduction to the Revised Edition. In: . (Comp.) New Atlantis and The Great Instauration. Wheeling: Harlan Davidson, 1989.

WYNNE, B. Seasick on the Third Wave? Subverting the Hegemony of Propositionalism: response to Collins and Evans (2002). Social Studies of Science, Los Angeles, London, New Dheli, Singapore, v.33, n.3, p.401-17, June 2003.

RESUMO - O artigo recupera momentos-chave do debate sobre as relações entre ciência e política, expertise e democracia, concentrando-se em diversos autores e disciplinas das ciências humanas. O objetivo é esclarecer as origens e a substância dos atuais debates sobre a "democratização da expertise", assim como discutir alternativas para se lidar com o problema da aparente incompatibilidade entre as demandas por maior participação pública nas sociedades democráticas contemporâneas e a crescente importância da técnica e do conhecimento especializado para seu funcionamento. Enfatiza-se, especialmente, a forma como esse problema tem sido pensado no que diz respeito a temas da ciência e da tecnologia.

PALAVRAS-ChaVE: Ciência, Expertise, Democracia, Participação pública, Estudos sociais da ciência e da tecnologia.

ABSTRACT - This article lays out important moments of the debate on the relations between science and politics, expertise and democracy, by looking at several authors and disciplines within the human sciences. The purpose is to clarify the origins and substance of contemporary debates on the "democratization of expertise", as well as to discuss alternatives to deal with the problem of the apparent incompatibility between demands for further public participation in contemporary democratic societies and the increasing importance of specialized knowledge for their operation. I highlight how this problem has been approached with regards to issues of science and technology.

KEYWORDS: Science, Expertise, Democracy, Public participation, Social studies of science and technology.

Maya Mitre é doutora em Ciência Política pela Universidade Federal de Minas Gerais (UFMG). @-mayamitre@gmail.com

Recebido em 2.3.2012 e aprovado em 15.10.2013.

${ }^{\text {I } U n i v e r s i d a d e ~ F e d e r a l ~ d e ~ M i n a s ~ G e r a i s, ~ B e l o ~ H o r i z o n t e / M i n a s ~ G e r a i s, ~ B r a s i l . ~}$ 